\title{
PENINGKATAN KEMAMPUAN ORANG TUA DALAM MENGENDALIKAN ANAK-ANAK UNTUK MENGAKSES KONTEN PORNOGRAFI
}

\author{
Saut Pintubipar Saragih \\ Universitas Putera Batam (UPB), Batam, Indonesia \\ e-mail: saut@puterabatam.ac.id \\ Irene Svinarky \\ Universitas Putera Batam (UPB), Batam, Indonesia \\ e-mail: irene@puterabatam.ac.id \\ Mesri Silalahi \\ Universitas Putera Batam (UPB), Batam, Indonesia \\ e-mail: mesri@puterabatam.ac.id
}

\begin{abstract}
Smartphone and computer are commonly tool that people used in any stage of age including children who needs very strict and tight controlling. These technological devices are used for education, business, or social media purposes. In this community service we concern for the children that could lead them to illegal action during using their smartphones or computers such as visiting pornography websites, visiting piracy or dark websites, and lastly surfing illegal websites. Besides positives useful things of the internet technology, Accessing internet without control and supervision has negative risk too, users will have high possibility chances to access or viewing an adult content or pornography websites by their own purpose or just in coincidence moments. The objective of this program is to bring awareness and transfer the knowledge to all participant (parents) technically about setting up smartphones and computer's features to optimize the parent controlling. Parents will be teaching how to set up the parental feature in their children account, tracing the websites had visited by their teenage children, activate feture to block application, and limits their access to overused application. At the end of this community service will be able to perform their parental control of their teenagers' children and avoid them to access the pornography or adult content.
\end{abstract}

Keywords_parental_control, websites, internet, pornography

\section{PENDAHULUAN}

$\mathrm{D}$ ilihat dari perkembangan media saat sekarang ini yang mana dengan adanya kemudahan akses berbagai siaran yang pantas atau tidak pantas untuk terpublikasi baik dari dalam negeri maupun luar negeri, harusnya membuat masyarakat dapat menyaring informasi ataupun gambar dan konten yang mengandung pornografi apakah pantas atau tidak untuk dilihat (Chhachhar, Qureshi, Maher, \& Ahmed, 2014). Namun disisi lain apabila dilihat oleh anak yang belum cukup umur maka hal ini akan merubah cara berfikir dari anak-anak tersebut, karena mereka belum sesuai dengan umurnya melihat sesuatu yang menjadi tontonan orang dewasa. Kemajuan informasi seharusnya masyarakat 
lebih cepat mengetahui bagaimana cara menutup akses dari website yang mengandung unsur pornografi atau porno aksi, karena tidak mungkin melarang orang yang mengupload tontonan atau gambar maupun konten yang berbau pornografi tersebut. Dampak buruk yang nanti bisa dirasakan oleh anak-anak yang menontonnya seperti, suka menghayal, lebih cepat bertingkah seperti dewasa, suka melecehkan, berbicara sudah kearah pornografi, melakukan hubungan suami dan istri sebelum menikah dan masih banyak hal lain yang dapat dilakukan akibat pengaruh menonton hal-hal yang berbau pornografi. Bagi anak-anak yang belum dewasa menonton hal yang belum pantas dilihatnya maka akan menimbulkan dampak tidak baik. Menurut penulis dibalik kemudahan yang dapat dirasakan dalam menemukan akses website dan mudah mendapatkan informasi masih banyak juga kekurangan yang terdapat dari media sosial apabila tidak dipergunakan dengan baik. Kekurangan pengetahuan masyarakat terhadap penggunaan media online yang baik, membuat Tim Pengabdi tertarik untuk memberikan pembinaan Kepada masyarakat mengenai Parental control berbasis android untuk mencegah akses konten pornografi karena mengetahui sendiri bahwa gadget merupakan suatu barang kebutuhan pada saat sekarang ini sekaligus memberikan pembinaan mengenai bahaya dari pornografi. Pornografi dapat tersebar melalui media, mulai dari buku, majalah, film dan video. Salah satu yang paling umum sarana penyebaran pornografi adalah Internet, hal ini konsisten dengan jumlah pengguna yang mengakses internet berdasarkan kelompok umur yakni $85.4 \%$ adalah anak berusia 17-24 tahun (statista, 2019).

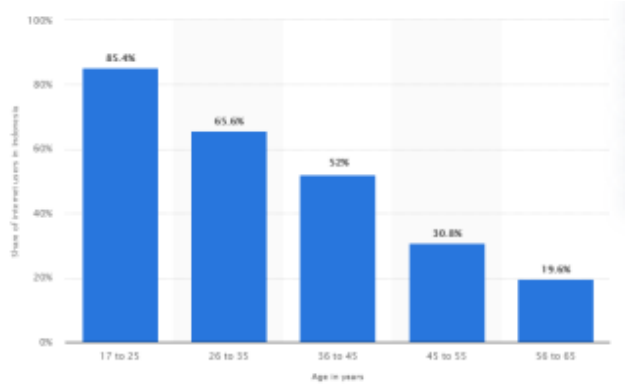

Gambar 1. Kelompok umur pengguna internet (statista, 2019)

Fakta yang ada keterkaitan dengan pornography berdasarkan data yang dikumpulkan oleh ConvententEyes dan IPS (internet pornography statistic) pada tahun dimana ada keuntungan yang diperoleh oleh pengguna untuk tujuan pornography terhadap anak-anak atau pengguna internet dibawah umur (Mahmoud, Abd-El-Hafeez, \& Omar, 2014). Penggunaan internet seperti platform social media terkadang menampilkan hal yang terlalu bebas, dikarenakan pengguna media sosial berasal dari berbagai negara yang memungkinkan konten pornography tampil dalam hasi pencarian di internet. Disisi lain media Internet yang secara sistematis dibangun untuk mempercepat distribusi informasi dari pengirim kepada penerima informasi tersebut juga sering disalahgunakan oleh beberapa pihak, baik sengaja ataupun tidak sengaja. Batasan akses internet seperti yang ada di Indonesia tertulis dalam undang-undang informasi, teknologi dan elektronik dimana ada beberapa jenis layanan yang dilarang untuk tampil pada penyedia informasi untuk publik seperti media website atau televisi.

Namun kewaspadaan juga harus tetap dimiliki oleh para orang tua agar selalu memantau kegiatan anak-anak mereka yang menjadikan gedjet menjadi 
bukan barang mahal lagi tetapi menjadi barang kebutuhan sehari-hari, sehingga dapat mengantisipasi dampak yang akan ditimbulkan dari konten pornografi yang muncul pada tontonan mereka. Keluarga atau orang tua memiliki tanggung jawab dan kewajiban untuk mengambil tindakan pencegahan untuk anak-anak mereka (Çankaya \& Odabaúı, 2009).

Mereka harus menetapkan aturan untuk anak-anak mereka tentang perilaku online tertentu seperti berbicara tentang seks dengan dan mengirimkan informasi pribadi kepada seseorang yang ditemui secara online, dan harus mendidik mereka tentang potensi bahaya yang terkait dengan kegiatan tersebut. Kewaspadaan dari sejak dini jauh lebih baik dari pada sudah terlambat, dimana perbuatan yang akan dapat timbul akibat menonton tontonan/konten pornografi yang belum pantas ditonton oleh anak-anak terhadap kurangnya pengawasan orang tua adalah: Dapat melecehkan orang lain, melakukan hubungan suami istri di luar nikah dan masih banyak yang lainnya. Kegiatan pengabdian Kepada masyarakat ini akan menargetkan peserta yang sudah memiliki anak yang bisa mengoperasikan smartphone. Tujuan dari kegiatan ini adalah mengajarkan cara pencegahan mencegah untuk tidak mengakses internet yang mengarah pada konten pornography. Tujuan dari kegiatan ini juga agar adanya pengetahuan terhadap perkembangan zaman yang terjadi terus menerus, dimana hal ini tidak mungkin dihentikan namun mencegah pornography yang sering sekali dapat ditemui di dunia nyata ataupun dunia maya merupakan sebuah bentuk rantai bisnis atau ekonomi pada aspek tertentu. Namun dalam menjaga anak-anak yang belum pantas untuk mengakses apa yang mereka belum pantas lihat, merupakan bagian dari tanggung jawab orang tua sebelum anak-anaknya nanti sudah mendapatkan pengetahuan dari luar lingkungan keluarganya. Kegiatan pengabdian kepada masyarakat ini akan dilaksanakan dengan metode yang diharapkan mamudahkan peserta untuk memahami dan akhirnya mampu mengendalikan akses internet terhadap domain yang mengandung unsur pornografi.

\section{METODE}

\subsection{Waktu Dan Tempat Pelaksanaan}

Pengabdian dilaksaakan kurang lebih 2 minggu di masyarakat, dilihat dari waktu yang telah ditentukan oleh Lembaga Penelitian dan Pengabdian Kepada Masyarakat, setiap pengusul memiliki waktu selama 2 jam /minggu untuk memberikan Pembinaan. Tempat yang akan dituju dalam pelaksanaan pengabdian kepada masyarakat yaitu: Tembesi Lestari, RT 003 RW 004 Kelurahan Tembesi Kecamatan Sagulung.

Tabel 1. Waktu dan tempat pelaksanaan

\begin{tabular}{l|c|c|l}
\multicolumn{1}{c}{ No } & \multicolumn{1}{c}{ Pertemuan } & \multicolumn{1}{c}{ Waktu } & \multicolumn{2}{c}{ Tempat } \\
\hline $\mathbf{1}$ & 17 Januari 2021 & $14.30-17.10$ & $\begin{array}{l}\text { Perumahan warga di RT 02 RW } \\
26 \quad \text { Kelurahan Buliang, } \\
\text { Kecamatan Batu aji. }\end{array}$ \\
\hline $\mathbf{2}$ & 7 Februari 2020 & $14.15-17.30$ & $\begin{array}{l}\text { Gedung Mesjid, Perumahan RT } \\
\text { 02 RW 26 Kelurahan Buliang, } \\
\text { Kecamatan Batu aji. }\end{array}$ \\
\hline
\end{tabular}




\subsection{Metode Pelaksanaan}

Kegiatan pengabdian ini dilaksanakan dengan menggunakan metode pengajaran secara langsung yaitu bertatap muka dengan mematuhi protokol Kesehatan. Pada Pertemuan Pertama, dilaksanakan pada 17 Januari 2021, 14.30-17.10. Pada pertemuan ini disampaikan ceramah dan pengenalal terhadap bahaya pornografi dari akses yang dapat dijangkau dikarenakan kecanggihan teknologi yang disalahgunakan pemakaiannya seperti gedjet yang digunakan oleh anakanak yang tidak sengaja membuka tontonan yang mengandung pornografi namun tidak sesuai dengan umur anak yang menonton tontonan tersebut. Anggota Kedua memberikan gambaran mengenai cara melakukan penutupan akses tontonan yang mengarah kearah pornografi atau konten porno.

Kegiatan dilanjutkan pada pertemuan kedua yang dilaksanakan pada 7 Februari 2020, pukul 14.15-17.30, pada pertemuan ini tim pelaksana memberikan pelatihan secara langsung bagaimana cara mengaktifkan fitur-fitur parental control pada gadget smartphone yang dimiliki oleh anak-anak atau orang tua. Peralatan yang digunakan pada pelatihan ini adalah smartphone dan sebuah unit komputer. Platform yang akan dilatih untuk dibuat pengaturannya adalah google, youtube dan aplikasi pada smartphone. (statista, 2019)

\subsection{Evaluasi Kegiatan}

Untuk evaluasi secara umum Tim Pengabdi ketika nantinya telah melaksanakan kegiatan pembinaan dipertemuan akhir maka Tim Pengabdi memiliki rencana selain memberikan bebapa pertanyaan berupa objektif kepada ibu-ibu perumahan tembesi lestari maka tim juga ingin melihat apakah masyarakat mengerti dengan pembinaan yang tim telah berikan. Pelaksanaan tersebut akan dipertanyakan kembali oleh tim Pengabdi dalam pemahaman ibuibu baik itu praktek dan teori yang disampaikan. Pengujian berupa test yang direncanakan akan dilakukan bertujuan untuk mengukur sejauh mana peserta memahami materi yang disampaikan oleh tim pengabdi.

\subsection{Keberlanjutan Kegiatan}

Pada kegiatan perngabdian ini untuk tim pangusul akan melihat beberapa hasil dan terget capaian yang disesuai dengan tujuan dari kegiatan pelatihan ini dan merencanakan apakah akan dibutuhkan keberlanjutan kegiatan untuk transfer pengetahuan ke area pengetahuan yang lebih jauh atau diadakan kerja sama dalam memberikan pelatihan secara menyeluruh dalam bidang umum disiplin ilmu informasi teknologi dan sistem informasi atau terkait dengan parental controlling.

\subsection{Waktu dan Tempat Pelaksanaan}

Kegiatan pengabdian Kepada masyarakat ini dilaksaakan sebanyak 2 kali pertemuan dengan masing-masing pertemuan selama dua jam atau lebih. Waktu pelaksanaan telah dikoordinasikan oleh ketua RT di perumahan tersebut. Berdasarkan jadwal pelaksanaan yang telah ditentukan oleh Lembaga Penelitian dan Pengabdian Kepada Masyarakat, tim pengabdi memiliki waktu 2 jam /minggu untuk memberikan pembinaan atau pelatihan. Tempat dan lokasi pelaksanaan pengabdian kepada masyarakat yaitu perumahan tembesi lestari, RT 003 RW 004 Kelurahan Tembesi Kecamatan Sagulung. 


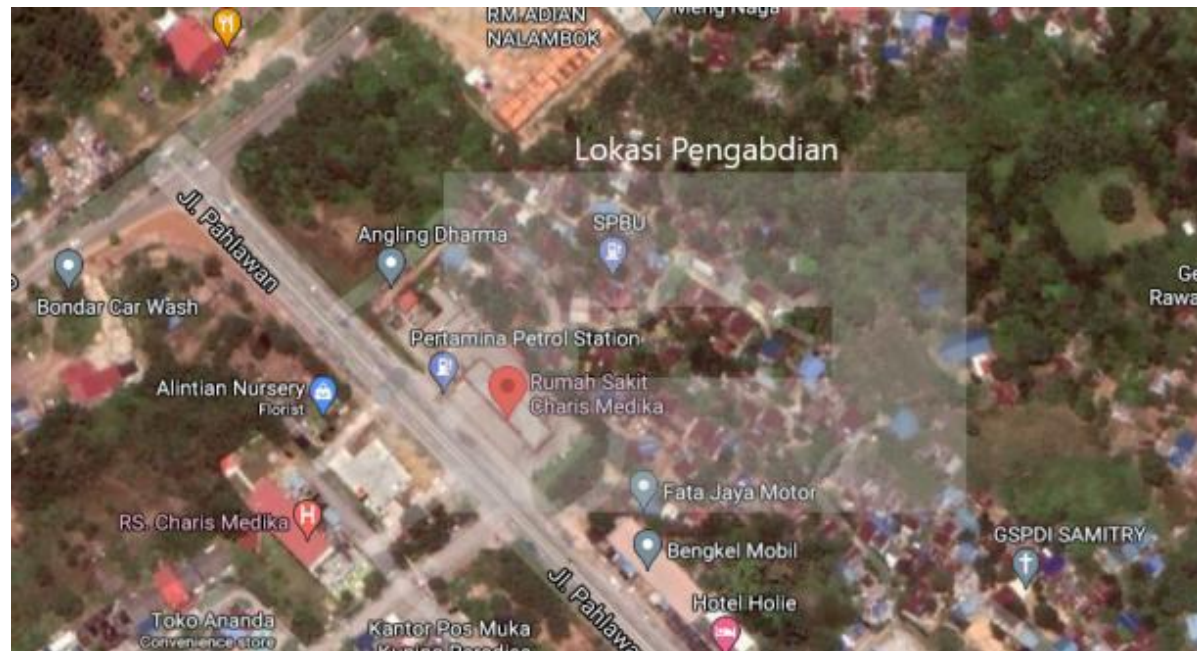

Gambar 2. Lokasi Pengabdian

Waktu pelaksanaan kegiatan pelatihan ini dapat dilihat pada tabel jadwal sebagai berikut:

Tabel 2. Jadwal kegiatan pelaksanaan Pengabdian Kepada Masyarakat

\begin{tabular}{|c|c|l|c|}
\hline Pertemuan & \multicolumn{1}{|c|}{ Tanggal } & \multicolumn{1}{|c|}{ Tempat } & Peserta \\
\hline $\mathbf{1}$ & 17 Januari 2021 & $\begin{array}{l}\text { Balai Masyarakat, } \\
\text { Perumahan Tembesi } \\
\text { Lestari, RT 003 RW 004 } \\
\text { Kelurahan Tembesi } \\
\text { Kecamatan Sagulung. }\end{array}$ & $\begin{array}{c}\text { Orang Tua } \\
\text { dan anak- } \\
\text { anak }\end{array}$ \\
\hline $\mathbf{2}$ & 7 Februari 2021 & $\begin{array}{l}\text { Perumahan Tembesi } \\
\text { Lestari, RT 003 RW 004 } \\
\text { Kelurahan Tembesi } \\
\text { Kecamatan Sagulung. }\end{array}$ & $\begin{array}{c}\text { Orang Tua } \\
\text { dan anak- } \\
\text { anak }\end{array}$ \\
\hline
\end{tabular}

\subsection{Metode Pelaksanaan}

Metode pelaksanaan kegiatan pengabdian kepada masyarakat ini ada dua metode pelaksanaan yaitu sebagai berikut:

\subsubsection{Ceramah}

Metode pengabdian ini akan fokus terhadap pemaparan data-data terkini terkait dengan penyalahgunaan smartphone terhadap akses internet oleh anakanak, ceramah juga akan memberikan pemahaman terhadap orang tua bahwa kecanggihan teknologi yang disalahgunakan pemakaiannya seperti gadget yang digunakan oleh anak-anak yang tidak sengaja membuka tontonan yang mengandung pornografi namun tidak sesuai dengan umur anak yang menonton tontonan tersebut sangat beresiko untuk mereka, tim pengabdi juga akan memberikan pengertian dan pemaparan data terhadap pengguna internet dan bagaimana internet digunakan secara tidak baik oleh anak-anak. Ceramah ini juga akan berfokus pada orang tua yang sebaiknya menggunakan pola asuh yang cerdas karena akan sangat berpengaruh pada individu anak. Membiarkan anak menggunakan gadget dalam waktu lama atau berlebihan akan membuat anak menjadi kecanduan gadget dan berdampak negatif pada perkembangan 
emosinya serta kurang memahami penyesuaian sosial di lingkungan karena kurangnya interaksi (Suhana, 2018)

\subsubsection{Praktik}

Pada sesi ini tim pengadi akan memberikan pelatihan secara langsung terhadap seluruh peserta agar pada akhir kegiatan mampu melakukan pengaturan pada smrtphone dan computer dalam menerapkan pengawasan terhadap anak dari akses pornography dan juga penggunaan yang berlebihan dari perangkat pintar atau smartphone. Beberapa topik pelatihan adalah mengaktifkan fitur parental control, sinkronisasi data smartphone anak dengan orang tua, membaca sejarah pencarian anak-anak, menutup akses terhadap aplikasi yang ada pada smartphone dan juga mengatur aplikasi agar terbatas dalam akses yang tidak sesuai umur.

\subsubsection{Peralatan dan kelengkapan pelatihan}

Untuk mensukseskan kegiatan ini maka tim pengabdi menggunakan beberapa peralatan yaitu sebagai berikut:
i. Smartphone
ii. Komputer
iii. Wifi repeater
iv. Modul (materi)
v. Buku Catatan

\subsection{Evaluasi Kegiatan}

Untuk evaluasi secara umum tim pengabdi ketika nantinya telah melaksanakan kegiatan pembinaan dipertemuan akhir maka Tim Pengabdi memiliki rencana selain memberikan bebapa pertanyaan berupa objektif kepada ibu-ibu perumahan tembesi lestari maka tim juga ingin melihat apakah masyarakat mengerti dengan pembinaan yang tim telah berikan. Pelaksanaan tersebut akan dipertanyakan kembali oleh tim pengabdi dalam pemahaman ibuibu baik itu praktek dan teori yang disampaikan. Pengujian berupa test yang direncanakan akan dilakukan bertujuan untuk mengukur sejauh mana peserta memahami materi yang telah disampaikan.

\section{HASIL DAN PEMBAHASAN}

Kegiatan yang sudah direncanakan dan dikoordinasikan dengan pihak masyarakat berjalan dengan harapan bahwa seluruh materi akan tersampaikan Kepada peserta dengan baik dan sesuai dengan tabel kegiatan yang telah disusun. Berikut merupakan hasil dari kegiatan yang berhasil dilaksanakan oleh tim pengabdi:

\subsection{Hasil Kegiatan}

Pada saat ini intenet merupakan salah satu media yang paling banyak diakses oleh berbagai kalangan khususnya anak-anak dikarenakan kondisi pandemi covid-19 yang mengharuskan anak-anak sekolah harus belajar online dari rumah. Kondisi ini mengakibatkan akses internet yang tidak bisa dihindari, internet banyak membantu anak-anak sekolah dalam mendukung pembelajaran mereka. Internet juga mempermudah proses belajar mengajar yang dilakukan. Berdasarkan analisis situasi maka diidentifikasi beberapa permasalahan, yaitu tingginya akses internet oleh anak-anak sekolah mengakibatkan besarnya 
peluang akses konten-konten negatif yang dilakukan oleh anak-anak, lemahnya pengetahuan orang tua tentang pentingnya pengawasan terhadap akses internet yang dilakukan oleh anak terbatasnya kemampuan penggunaan gadget oleh orang tua, terbatasnya skills orang tua dalam menggunakan aplikasi parental control berbasis android anak-anak dengan atau tidak sengaja mengakses konten-konten pornografi. Cara aman berinternet untuk anak adalah dengan menggunakan parental software pada gadget mereka ada 3 fungsi utama parental software yakni untuk filtering, supervising (pengawasan), scheduling (penjadwalan). Masing-masing gadget sudah dilengkapi dengan fitur parental control. Pesreta hanya perlu untuk mengaktifkannya saja. Di Mac OS, caranya masuk ke System Preferences panel atau Control Panel pada halaman Windows. Bisa juga menggunakan aplikasi tambahan yang banyak tersedia di platform penyedia aplikasi seperti playstore atau Appstore.

\subsubsection{Ceramah tentang pornography pada internet dan media lainnya.}

Untuk mengatasi permasalahan yang dihadapi oleh masyarakat pada objek pengabdian maka solusi yang diberikan yaitu Memberikan pembinaan cara meningkatkan pengetahuan dan kesadaran orang tua tentang pentingnya parental control tentang akses internet yang dilakukan oleh anak-anak. Memberikan pembinaan terkait konten pornografi melalui internet memberikan pembinaan tentang aplikasi parental control yang cocok digunakan untuk orang tua Memberikan pelatihan penggunaan aplikasi parental control berbasis android pada orang tua. Pornografi merupakan bahaya laten yang ditakutkan oleh sebagian besar orang tua (Ulinnuha, 2013). Karena dapat mempengaruhi perkembangan anak. Anak-anak menjadi target utama dalam bisnis pornografi. Dalam menggunakan teknologi gawai, anak biasanya membuka game online, video animasi dan situs intenet lainnya. Menggunakan gawai tersebut kadang tanpa pengawasan dari orang tua. Disadari atau tidak, situs online banyak mengandung unsur pornografi. Pornografi adalah materi seksualitas yang dibuat oleh manusia dalam bentuk gambar, sketsa, ilustrasi, foto, tulisan, suara, bunyi, gambar bergerak, animasi, kartun, syair, percakapan, gerak tubuh, atau bentuk pesan komunikasi lain melalui berbagai bentuk media komunikasi dan/atau pertunjukan di muka umum, yang dapat membangkitkan hasrat seksual dan/melanggar nilai-nilai kesusilaan dalam masyarakat.

\subsubsection{Pelatihan untuk membuat profil pengguna pada smartphone}

Hal ini diberikan Kepada peserta untuk membuat sebuah pengaturan tertentu pada profil pengguna smartphone yang akan digunakan oleh anak-anak. Fitur ini disebut dengan retricted profile yang mana membatasi aplikasi yang akan terpasang pada smartphone yang digunakan oleh anak-anak. Peserta diberikan pelatihan dengan mengikuti tahapan sebagai berikut:

i. Pertama sekali peserta diminta menemukan ikon (gambar kecil) berbentuk gigi roda di layar, atau panel notifikasi, atau ruang tempat aplikasi, kemudian ketuk ikon tersebut untuk membuka menu settings (pengaturan).

ii. Langkah selanjutnya kemudian peserta menggeser layar, lalu memilih pilihan users.

iii. Setelah itu peserta menambahkan pengguna dengan hak akses terbatas (restricted puser) dengan memilih "Add user or profile", kemudian pilih pilihan Restricted profile.

iv. Kemudian setelah itu pesrta diminta menambahkan kata sandia atau pin atau pola untuk keamanan atau privasi pengguna smartphone nantinya. 
v. Setelah langkah iv, kemudian peserta diminta untuk memberikan nama profil yang akan digunakan untuk profil tersebut, misalnya nama profil belajar atau yang lainnya

vi. Kemudian peserta memilih pilihan aplikasi (application) untuk memilih aplikasi mana saja yang akan diijinkan untuk dibuka Ketika profil tersebut diaktifkan

vii. Kemudian peserta bisa menggunakan profil tersebut setelah keluar dari tampilan pengaturan (setting)

\subsubsection{Pelatihan mengaktifkan parental control pada smartphone}

Parental control merupakan fitur pengendalian orang tua (parental control) yang ada pada setiap smartphone. Fitur ini dapat digunakan peserta pelatihan untuk mengendalikan penggunaan aplikasi yang ada pada smartphone anak-anak mereka (https://google.com/, 2020). Berikut Langkah-langkah yang digunakan oleh peserta untuk mengaktifkannya:

i. Membuka menu pengatura (setting)

ii. Peserta memilih pilihan parental controls pada bagian user' controls (pengaturan pengguna)

iii. Pada bagian akhir peserta dapat mengaktifkan fitur tersebut dengan menggeser tombol on dan off.

iv. Pada menu yang sama peserta dapat mengaktifkan konten terbatas seperti aplikasi dan konten lainnya.

v. Setelah langkah tersebut dilakukan maka tombol save harus ditekan untuk menyimpan pengaturan.

\subsubsection{Pelatihan mengaktifkan parental control pada playstore (android)}

Playstore merupakan sebuah marketplace dimana semua pengguna android mengunduh dan memasang segala jenis aplikasi. Ada sangat banyak jenis aplikasi yang tersedia, sehingga anak-anak bisa memasang jenis aplikasi sesuai keinginannya. Namun hal tersebut dapat dicegah dengan mengaktifkan fitur parental controls pada playstore. Peserta menggunakan langkah-langkah sebagai berikut untuk mengaktifkan fitur tersebut:

i. Peserta membuka aplikasi google playstore.

ii. Peserta memilih memilih logo garis tiga di pojok kanan atas dan masuk ke bagian Settings.

iii. Kemudian pesrta memilih menu Parental Control dan mengaktifkan fitur tersebut.

iv. Langkah selanjutnya adalah membuat pin untuk mengkatifkan fitur tersebut.

v. Setelah langkah tersebut dilakukan maka peserta memilih kategori yang ditentukan sesuai dengan batasa umur.

vi. Setelah langkah tersebut dilakukan maka tombol save harus ditekan untuk menyimpan pengaturan.

vii. Setelah langkah tersebut maka peserta sudah membuat pengaturan untuk membatasi aplikasi yang akan muncul pada playstore pada smartphone anak-anak.

viii. Hasilnya akan bisa dilihat dimana pada tampilan aplikasi play store hanya akan terlihat aplikasi untuk umur yang telah ditentukan. 


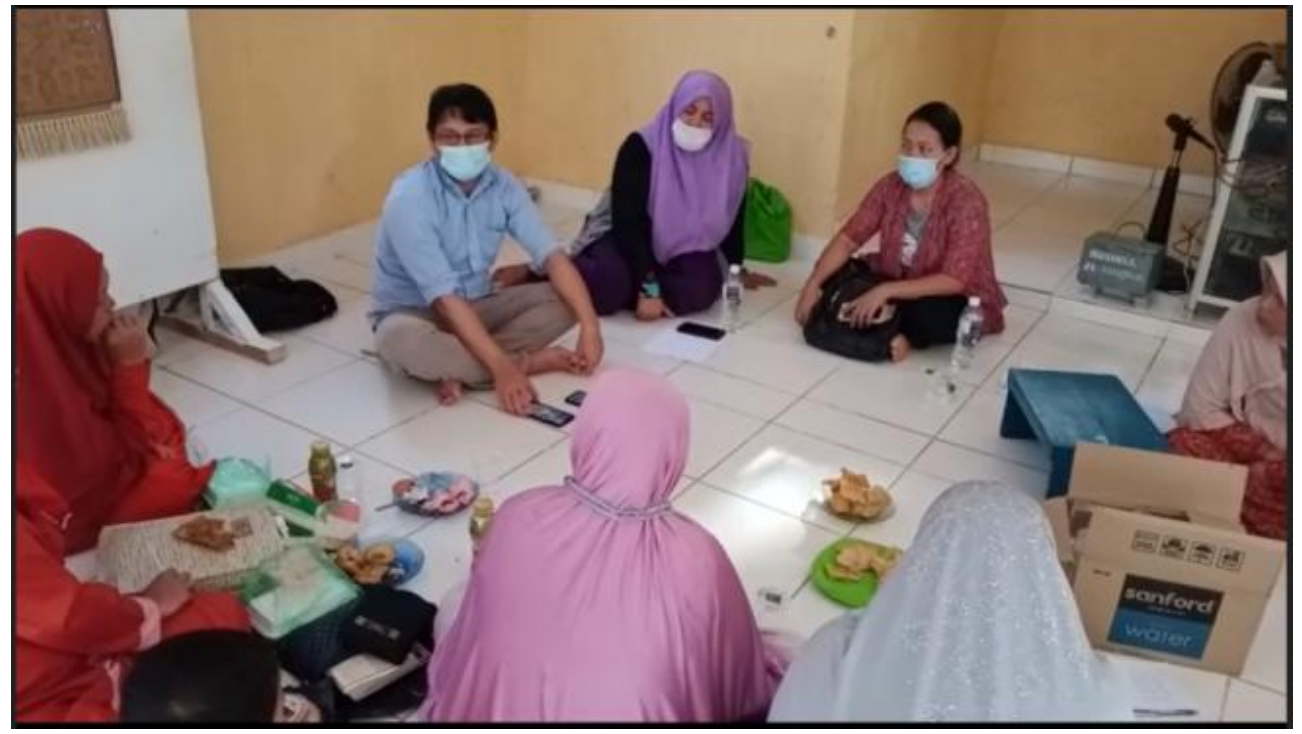

Gambar 3. Tim pengabdian melakukan pelatihan Kepada peserta

\section{KESIMPULAN}

Kegiatan telah selesai dilaksanakan dalam 2 kali pertemuan dan masingmasing pertemuan diadakan selama 2 sampai 3 jam. Peserta telah mampu mempraktikan pengaturan parental control pada smartphone dimana diantaranya adalah mengaktifkan fitur parental control pada smartphone untuk membatasi anak-anak dalam mengakses konten dewasa pada smartphone terutama pada browser. Kemudian peserta juga sudah mampu untuk melakukan pengaturan dengan cara mengaktifkan fitur parental control pada layanan play store sehingga bisa membatasi jenis aplikasi yang digunakan oleh ana-anak. Kegiatan ini berjalan dengan baik dengan seluruh rencana kegiatan telah dilaksanakan dengan baik oleh tim pengabdian dan juga diikuti oleh peserta dengan baik.

\section{SARAN}

Hasil pengabdian yang telah dilaksanakan mencapai target pengabdian yaitu memberikan pelatihan Kepada peserta untuk menggunakan teknologi dalam melakukan parental controlling. Peserta telah mampu melakukan pengaturan terhadap perangkat gadget yang digunakan oleh anak-anak mereka. Tim pengabdian menyarankan agar pengabdian ini terus berlanjut secara linier agar pengetahuan pesrta lebih lengkap. Tim pengabdian menyarankan agar melakukan pelatihan dalam membangun sebuah family controlling dan parental controlling dalam skala yang lebih luas seperti pada personal computer atau laptop serta gadget lainnya selain smartphone.

\section{UCAPAN TERIMA KASIH}

Penulis mengucapkan terima kasih kepada Lembaga Penelitian dan Pengabdian Masyarakat Universitas Putera Batam, Pihak pihak pengurus mushola dan RT/RW di tembesi lestari, dan juga seluruh peserta yang telah mendukung terhadap pengabdian ini. 


\section{DAFTAR PUSTAKA}

Çankaya, S., \& Odabaúı, H. F. (2009). Parental controls on children's computer and Internet use. elsevier, 1105-1109.

Chhachhar, A. R., Qureshi, B., Maher, Z. A., \& Ahmed, S. (2014). Influence of Internet Websites on Children Study. Journal of American Science.

https://google.com/. (2020). Family Link. Retrieved from https://families.google.com/: https://families.google.com/familylink/\#

Mahmoud, T. M., Abd-El-Hafeez, T., \& Omar, A. (2014). An Efficient System for Blocking Pornography Websites. In M. Sarfraz, Computer Vision and Image Processing in Intelligent Systems and Multimedia Technologies.

statista. (2019). Share of internet users in Indonesia in 2019, by age group. Indonesia: statista.

Suhana, M. (2018). Influence of Gadget Usage on Children's Social-Emotional Development. Advances in Social Science, Education and Humanities Research, 224-227.

Ulinnuha, M. (2013). MELINDUNGI ANAK DARI KONTEN NEGATIF INTERNET: Studi terhadap Peramban Web Khusus Anak. SAWWA . 